\title{
Male circumcision and HIV infection among sexually active men in Malawi
}

\author{
Namuunda Mutombo ${ }^{1 *}$, Beatrice Maina ${ }^{2}$ and Monica Jamali ${ }^{3}$
}

\begin{abstract}
Background: The HIV epidemic remains a major health challenge all over the world. In 2013, an estimated 35million people were living with HIV globally. Male circumcision is increasingly being adopted as a method of HIV prevention. WHO and UNAIDS have advised that male circumcision be added to current HIV interventions. Malawi is one of the countries hardest hit by HIV/AIDS with a prevalence rate of $11 \%$ and male circumcision prevalence of $21.6 \%$ in 2010. Prior to 2011, traditional male circumcision in Malawi was the dominant form of male circumcision, mainly for cultural and religious reasons. This paper looks at male circumcision as a prevention method against HIV by examining the relationship between male circumcision and HIV status among Malawian men.
\end{abstract}

Methods: The data used were collected as part of the 2010 Malawi Demographic and Health Survey. The methodology used in the 2010 MDHS has been comprehensively described by the National Statistical Office of Malawi and ICF Macro. Our analysis is based on men aged 15-54 years who were tested for HIV and responded to questions on circumcision during the survey. Sixty one percent of the 7175 men interviewed in the MDHS, qualified for this analysis. The sample was weighted to ensure representativeness. Frequencies, cross-tabulations, univariate and multivariate logistic regressions were conducted. Differences in the prevalence of HIV infection among circumcised and uncircumcised men were determined with Chi-squared tests.

Results: There is no significant difference in HIV prevalence between circumcised (12\%) and uncircumcised men (10 \%). Among circumcised men, age and number of lifetime partners are the dominant correlates of HIV status. Additionally, circumcised men who have had ritual sex are two times more likely $(\mathrm{OR}=2.399)$ to be HIV+ compared to circumcised men who have never had ritual sex.

Conclusion: This study has demonstrated that traditional male circumcision was not associated with HIV infection in pre-2010 Malawi. Among circumcised men, age and number of lifetime partners are correlates to HIV status while circumcised men who have had ritual sex are more likely to be diagnosed with HIV than circumcised men who have not had ritual sex.

Keywords: HIV infection, HIV prevention, Malawi, Male circumcision, HIV risk

\section{Background}

The HIV epidemic remains a major health challenge all over the world. In 2013, the UNAIDS estimated 35million people were living with HIV globally; and in the same year, 2.1 million new HIV infections and 1.5 million AIDS related deaths occurred [1]. Recent studies have identified approaches for HIV prevention especially those that target the generalized epidemic in sub-Saharan Africa

\footnotetext{
* Correspondence: nmutombo@aphrc.org

'African Population and Health Research Center (APHRC), P.O Box 1078700100 Nairobi, Kenya

Full list of author information is available at the end of the article
}

and includes Comprehensive condom and lubricant programming, harm reduction for people who inject drugs, behavioral interventions, prevention of transmission in health-care settings, ARV-related prevention, and voluntary medical male circumcision for HIV prevention [2-7]. Results from randomized clinical trials conducted in Kenya, Uganda and South Africa established that male medical circumcision greatly reduced the risk of HIV infection among men $[3,8,9]$. Further studies have shown how those already infected can be treated $[2,10]$ or how the effects of the virus on a person's immunity can be minimized by avoiding reinfection $[8,11]$. As a result 
of the findings of the randomized clinical trials which showed that medical male circumcision can be used as a prevention measure for HIV infection $[3,8,9]$, the World Health Organization (WHO) and the Joint United Nations Programme on HIV/AIDS (UNAIDS) recently recommended that circumcision be added to current interventions to reduce the spread of HIV $[12,13]$. Male circumcision is defined as the complete removal of the foreskin [14]. Traditionally, many African societies have embraced male circumcision as a rite of passage from childhood to adulthood, rather than a medical operation [14] and also for religious and to a lesser extent, for medical purposes [15]. While not all communities practice circumcision, studies investigating HIV transmission done among communities practicing circumcision have consistently found that circumcision significantly reduces the rate of HIV transmission at the community level $[16,17]$.

In many of these studies, the outcome has been that circumcised men are significantly less likely to acquire HIV when exposed sexually to HIV-positive women as compared to men with intact foreskins $[3,8,9,18]$. Special phagocytic cells in the foreskin, Langerhans cells, are said to act as magnets to the virus which attaches to the cell and thus enters the body [19]. A recent review by Morris and Wamai termed the inner foreskin as a mucosal epithelium which is deficient in protective keratin but rich in HIV target cells [20]. Once exposed to infected mucosal secretions, infected T-cells combine with keratinocytes and then transfer HIV to Langerhans cells via dendrites just under the surface of the inner foreskin which then migrates to the basal epidermis and then pass HIV to T-cells leading to infection [20]. This is aggravated by occurrence of any inflammations and ulceration and also tearing of the foreskin during intercourse [20]. In addition, randomized trials of male circumcision showed that male circumcision significantly reduced the bacterial load by reducing both the prevalence and abundance of many coronal sulcus bacteria [21]. Nevertheless, male circumcision does not provide a complete prevention against HIV infection, and circumcised men can become infected, and can transmit the virus to their partners $[2,3,8,9]$.

However, there still remain gaps and unanswered questions relating to HIV transmission and circumcision. Although not supported by literature, one major concern is the behavioral disinhibition where circumcised men could feel more protected against HIV infection and hence may engage in a riskier behavior. Traditionally, and in some communities, young men are taken into seclusion and given advice touching on their responsibilities which includes their sexual behavior [14]. Though not well documented, its often assumed that these 'guidance and counseling' sessions inform or instill behavior change and risk reduction on HIV transmission among circumcised men as compared to the uncircumcised, who principally do not go through such sessions. However, cluster randomized trials done in South Africa to assess the interventions that could prevent men from sexual risky behaviors after circumcision showed that social cultural values dictated how men should behave among traditionally circumcised men [22] and hence resistance to change; while among those medically circumcised, a focused counseling session had short term effects on reducing risky sexual behavior [23]. During male circumcision rituals, the period of seclusion constitutes the most significant part where new attitudes, practices and behaviours are learnt which includes sexual issues [14]. Whereas sexual reserve and inappropriateness of promiscuity after reintegration into society are emphasized, in other contexts, boys are encouraged to have sex to prove their manhood even during the seclusion period, often referred to as ritual sex [14]. Ritual sex is practiced in many African communities and is associated with traditional circumcision where men are "cleansed through" and/or "trained on" sexual activities. Although ritual sex is conducted in some communities in Malawi, there is limited information regarding this practice. However, in Zambia, ritual sex is associated with traditional circumcision and use of condom is not emphasized [24, 25]. There is therefore a need to look at the association between type of circumcision and HIV infection in Malawi, as well as analyze the effect of ritual sex on HIV infection.

While some studies show that pre-pubertal circumcision is associated with reduced risk of HIV infection [26, 27], one study shows no significant association between age at circumcision and HIV infection [28]. Male circumcision in many African societies is done at puberty [29] ; however, there are communities that do not have a defined circumcision period and therefore some men are circumcised as infants, while others are circumcised at adulthood. When circumcised at old age, these men are already exposed to sexual activities for a long time, and have higher chances of being exposed to HIV as compared to younger men.

\section{Study setting and objectives}

Malawi is one of the countries hardest hit by HIV/AIDS. Though recent indicators have shown some decline from a prevalence rate of 11.8 to $10.6 \%$ in 2004 and 2010 respectively, a lot still needs to be done [30]. The 2012 AIDS Response Progress Report shows that Malawi has registered progress in the areas of prevention; treatment, care and support; and impact mitigation [30]. However, the country has been criticized for being slow in the introduction of free male circumcision in public facilities and only recently, in 2011, the Malawi government adopted a policy on medical male circumcision as part of its HIV prevention strategy, offering the service free at public hospitals [30]. But male circumcision has been in practice in Malawi for cultural and religious reasons [31] and only recently 
that men are embracing circumcision and mainly due to its medical advantage. According to WHO, voluntary medical male circumcision (VMMC) in Malawi has been rising slowly from less than 600 men in 2008 to over 40,000 in 2013 and have obtained almost $4 \%$ progress towards achieving the $80 \%$ coverage by 2016 [32, 33]. Even though male circumcision is viewed as one of the key interventions on HIV prevention, no study has examined its effect within the Malawian context. The objective of this study is to evaluate the relationships between male circumcision and HIV status among Malawian men before the implementation of VMMC using data from the 2010 Malawi Demographic and Health Survey (MDHS).

\section{Methods}

\section{Data source and sample size}

This paper uses cross-sectional data from the nationally representative sample of the 2010 MDHS Men's File to examine the association between male circumcision and HIV status in Malawi. The methodology used in the 2010 MDHS has been comprehensively described by the National Statistical Office of Malawi and ICF Macro [34]. The primary objectives of the 2010 MDHS project were to provide up-to-date information on fertility levels; nuptiality; sexual activity; fertility preferences; awareness and use of family planning methods; breastfeeding practices; nutritional status of mothers and young children; early childhood mortality; maternal mortality; maternal and child health; malaria; awareness and behavior regarding HIV/ AIDS and other sexually transmitted infections; and HIV prevalence. This was a nationally representative survey whose sample design was tailored to provide specific indicators at national and regional levels. A total of 23,020 women (15-49) and 7175 men (15-54) were interviewed from 24,825 households using the Woman's and Man's Questionnaires, respectively. This paper is based on men (15-54) who tested for HIV and responded to questions on circumcision during the survey. Out of the 7175 men interviewed in the MDHS, 4358 (61 \%) men were valid for this analysis. The sample was weighted using the DHS generated survey weights to ensure representativeness.

\section{Ethics statement}

The 2010 MDHS was approved by Malawi Health Sciences Research Committee, the Institutional Review Board of ICF Macro, and the Centre for Disease Control and Prevention $(C D C)$ in Atlanta. Use of the MDHS data was communicated to and permission to use granted by Measure DHS.

\section{Variables}

The dependent variable used is HIV status. This variable is measured as a dichotomous variable and is coded as negative status and positive status. Four models were applied to assess the correlates of HIV status. These models are: I) unadjusted analysis of HIV correlates among circumcised and uncircumcised men; II) adjusted analysis of HIV correlates among circumcised and uncircumcised men; III) adjusted analysis of HIV correlates among circumcised men; and IV) adjusted analysis of HIV correlates among uncircumcised men.

The main independent variable is the circumcision status i.e. circumcised or not circumcised. The control variables used in the study are: age, marital status, age at sexual debut, ever had ritual sex, number of lifetime partners, type of residence, region of residence, religion, level of education and wealth index. The confounding factors in the study are age at circumcision, and type of circumcision, which are only used in Model IV as they only apply to the circumcised group. The wealth index was constructed from the wealth quintile as follows: 1st and 2nd quintiles (poor); 3rd quintile (medium); and 4th and 5th quintiles (rich).

\section{Data analysis}

In order to ascertain the effect of circumcision on HIV status among Malawian men (15-54), we used the Statistical Package for Social Sciences (SPSS) to generate frequencies, cross-tabulations and binary logistic regressions. The Chi-Square test was used to determine the level of association between the dependent and independent variables.

The odds ratio is used to depict the likelihood of a respondent testing positive for HIV. A ratio greater than 1 means greater likelihood of being HIV-positive than the reference category; a ratio less than 1 means lower likelihood of being HIV-positive than the reference category; and a ratio of 1 means same likelihood of being HIVpositive as the reference category. In this study, an independent variable is considered significant if its effect on the dependent variable (HIV status) is statistically significant at the 0.95 confidence interval (i.e. $p \leq 0.050$ ).

\section{Results}

\section{Characteristics of respondents}

Table 1 below shows distribution by selected background characteristics of men who responded to the circumcision question and had their blood sample taken for HIV testing. Almost $80 \%$ of the men were aged below 40 years; about $41 \%$ were never married; almost $97 \%$ initiated sex when aged below 25 years and one in every 25 men had participated in a ritual sex. Table 1 also shows that $83 \%$ of the men had more than one life time sex partners.

Slightly over $85 \%$ of men in the sample lived in rural areas with the Southern region having the highest percentage of men at $46 \%$, while the Northern region had the least at $17 \%$. Almost $90 \%$ of Malawian men were Christians, $61 \%$ had primary level education and only $34 \%$ were regarded as poor. On circumcision, over $80 \%$ 
Table 1 Distribution of respondents by selected background characteristics

\begin{tabular}{|c|c|c|}
\hline \multirow{2}{*}{$\begin{array}{l}\text { Background } \\
\text { characteristics }\end{array}$} & \multicolumn{2}{|c|}{ Sample size } \\
\hline & $\%$ & $n$ \\
\hline \multicolumn{3}{|l|}{ Age } \\
\hline $15-24$ & 35.2 & 1,533 \\
\hline $25-39$ & 43.9 & 1,911 \\
\hline $40+$ & 20.9 & 914 \\
\hline \multicolumn{3}{|l|}{ Marital status } \\
\hline Never married & 40.8 & 1,778 \\
\hline Currently married & 55.3 & 2,410 \\
\hline Formerly married & 3.9 & 170 \\
\hline \multicolumn{3}{|l|}{ Age at sexual debut } \\
\hline$<15$ & 21.0 & 915 \\
\hline $15-24$ & 75.6 & 3,294 \\
\hline $25+^{+}$ & 3.4 & 149 \\
\hline \multicolumn{3}{|l|}{ Ever had ritual sex } \\
\hline Yes & 3.6 & 159 \\
\hline No & 96.4 & 4,199 \\
\hline \multicolumn{3}{|c|}{ Number of life time partners } \\
\hline 1 & 17.2 & 750 \\
\hline 2 & 24.8 & 1,082 \\
\hline 3 & 21.3 & 921 \\
\hline 4 & 11.2 & 486 \\
\hline 5 & 8.5 & 371 \\
\hline $6-9$ & 9.0 & 394 \\
\hline $10+$ & 8.1 & 354 \\
\hline \multicolumn{3}{|l|}{ Type of residence } \\
\hline Urban & 14.8 & 647 \\
\hline Rural & 85.2 & 3,711 \\
\hline \multicolumn{3}{|l|}{ Region } \\
\hline Northern & 17.2 & 750 \\
\hline Central & 36.5 & 1,592 \\
\hline Southern & 46.3 & 2,016 \\
\hline \multicolumn{3}{|l|}{ Religion } \\
\hline Catholic & 22.6 & 984 \\
\hline Other Christian & 67.2 & 2,930 \\
\hline Muslim & 10.2 & 444 \\
\hline \multicolumn{3}{|l|}{ Level of education } \\
\hline None & 5.8 & 253 \\
\hline Primary & 61.2 & 2,669 \\
\hline Secondary+ & 33.0 & 1,436 \\
\hline \multicolumn{3}{|l|}{ Wealth index } \\
\hline Poor & 34.3 & 1,496 \\
\hline Medium & 20.7 & 903 \\
\hline Rich & 45.0 & 1,959 \\
\hline
\end{tabular}

Table 1 Distribution of respondents by selected background characteristics (Continued)

\begin{tabular}{lll}
\hline $\begin{array}{l}\text { Circumcision status } \\
\text { Circumcised } \\
\text { Age at circumcision }\end{array}$ & 19.1 & 831 \\
$\quad<10$ & 26.4 & 219 \\
$10-14$ & 52.0 & 432 \\
$15+$ & 21.6 & 180 \\
Type of circumciser & & \\
Traditional & 85.4 & 710 \\
$\quad$ Medical & 14.6 & 121 \\
Not circumcised & 80.9 & 3,527 \\
$\quad$ HIV status & & \\
Negative & 89.9 & $\mathbf{3 , 9 1 8}$ \\
$\quad$ Positive & 10.1 & 440 \\
Total & $\mathbf{1 0 0 . 0}$ & $\mathbf{4 , 3 5 8}$ \\
\hline
\end{tabular}

of Malawian men reported to have been uncircumcised at the time of the survey. Among the circumcised men, data show that most circumcised men (85\%) underwent traditional circumcision while the rest $(15 \%)$ underwent medical circumcision. The data further show that the majority ( $52 \%$ ) were circumcised between the ages of 10 and 14 while a quarter were circumcised before they were 10 years old. The rest (22\%) got circumcised at $15+$. Results of HIV testing showed that $10 \%$ of Malawian men were HIV positive at the time of the survey.

\section{Bivariate results}

Results in Table 2 show men's HIV status by background characteristics. Overall, $10 \%$ of men were HIV positive. Older men (40+), formerly married, men with more than four lifetime partners were more likely to be HIV positive compared to their counterparts $(P<0.001)$. Urban areas, and the southern region had significantly higher proportion of HIV + men $(P<0.001)$ compared to rural areas and Northern and Central regions respectively. The rich also were more likely to be $\mathrm{HIV}+$ as compared to medium rich and the poor $(P<0.001)$. Similarly, men who initiated sex when they were aged more than 24 years also were more likely to be $\mathrm{HIV}+(P<0.01)$. A significantly higher proportion of HIV+ men was also observed among the circumcised $(P<0.05)$ compared to the uncircumcised.

\section{Multivariate results}

Four regression models were fitted (Table 3). Model I is the unadjusted model while model II, III and IV are adjusted models representing both uncircumcised and circumcised men, uncircumcised men only and circumcised 
Table 2 Percent distribution of respondents by HIV status and selected background characteristics

\begin{tabular}{|c|c|c|c|}
\hline \multirow{2}{*}{$\begin{array}{l}\text { Background } \\
\text { characteristics }\end{array}$} & \multicolumn{2}{|l|}{ HIV status } & \multirow{2}{*}{$\begin{array}{l}\text { Sample } \\
\text { size }\end{array}$} \\
\hline & Negative & Positive & \\
\hline \multicolumn{4}{|l|}{$A g e^{* * *}$} \\
\hline $15-24$ & 97.8 & 2.2 & 1533 \\
\hline $25-39$ & 87.5 & 12.5 & 1911 \\
\hline $40+$ & 81.1 & 18.9 & 914 \\
\hline
\end{tabular}

\section{Marital status ${ }^{* * *}$}

Currently married

Formerly married

$<15$

$15-24$

$25+{ }^{+}$

Ever had ritual sex

$$
\text { Yes }
$$

No

Number of life time partners***

Type of residence ${ }^{* * *}$

Urban

Rural

Region***

Northern

Central

Southern

Religion

Catholic

Other Christian

Muslim

Level of education

None
Primary
Secondary+
Wealth index ${ }^{* *}$
Poor
Medium
Rich

\section{0}

1778

2410

170

Table 2 Percent distribution of respondents by HIV status and selected background characteristics (Continued)

\begin{tabular}{llll}
\hline Circumcision status* & & & \\
Circumcised & 87.9 & 12.1 & 831 \\
Not circumcised & 90.5 & 9.5 & 3,527 \\
Total & $\mathbf{8 9 . 9}$ & $\mathbf{1 0 . 1}$ & $\mathbf{4 , 3 5 8}$ \\
\hline${ }^{*} p<0.050 ;{ }^{* *} p<0.01 ;{ }^{* * *} p<0.001$ & &
\end{tabular}

men only, respectively. Model III and IV were used to depict the most influential variables among uncircumcised and circumcised groups. The unadjusted model shows that 8 out of the thirteen variables are significant on the likelihood of being HIV+. These variables are: age, marital status, age at sexual debut, number of lifetime sexual partners, residence, region, wealth index and circumcision status. However, when we control for other factors (Model II), only four variables remain significant on the likelihood of being HIV+. These are age, number of lifetime sexual partners, residence and region.

Men aged below 40 years were found to be strongly associated with decreased odds of being HIV+ compared to men aged 40 years and above. Men who had up to 4 lifetime sexual partners had lower odds of being HIV+ compared to those who had 5 or more lifetime sexual partners, while those residing in the urban areas were at least two times more likely to be HIV+ than their rural counterparts. Compared to men from the Southern region, men from the Northern and Central regions were almost $50 \%$ likely to be $\mathrm{HIV}+$. Even though circumcision was significant in Model I, it was not significant after controlling for other variables.

Table 3 also shows that the four significant variables in Model II produce similar effects in Model III. However, two additional variables, namely education and wealth index, are also significant on the probability of being diagnosed with HIV among the uncircumcised men: the higher the level of education the lower the odds of being $\mathrm{HIV}+$ while the level of wealth is directly related with the odds of being HIV+. In the fourth model, two more variables (ritual sex and religion) that were not significant in the other three models show strong association with the likelihood of being diagnosed with HIV among the circumcised men. Circumcised men who had ritual sex were at least 2 times more likely to be HIV+ compared to those who had not participated in ritual sex. A further analysis of ritual sex was done (data not shown in tables) to show the rates of ritual sex among the traditionally versus medically circumcised. The results showed that among circumcised men, reported ritual sex was $3.9 \%$. Among those circumcised traditionally, $4.4 \%$ reported having had ritual sex compared with $1.4 \%$ reported among the medically circumcised. Circumcised men of Catholic faith had at least 2 times higher odds of 
Table 3 Respondent's odds of being HIV-positive by selected background characteristics

\begin{tabular}{|c|c|c|c|c|c|c|c|c|}
\hline \multirow{2}{*}{$\begin{array}{l}\text { Background } \\
\text { characteristics }\end{array}$} & \multicolumn{2}{|l|}{ Model I } & \multicolumn{2}{|l|}{ Model II } & \multicolumn{2}{|l|}{ Model III } & \multicolumn{2}{|l|}{ Model IV } \\
\hline & $\overline{\operatorname{Exp} \beta}$ & $\mathrm{Cl}$ & $\operatorname{Exp} \beta$ & $\mathrm{Cl}$ & $\operatorname{Exp} \beta$ & $\mathrm{Cl}$ & $\operatorname{Exp} \beta$ & $\mathrm{Cl}$ \\
\hline \multicolumn{9}{|l|}{ Age } \\
\hline $15-24$ & $0.097^{* * *}$ & $.072-.132$ & $0.131^{* * *}$ & $.085-.200$ & $0.149^{* * *}$ & $.092-.240$ & $0.070^{* * *}$ & $.025-.197$ \\
\hline $25-39$ & $0.634^{* * *}$ & $.525-.766$ & $0.675^{* *}$ & $.538-.848$ & $0.610^{* * *}$ & $.610-.796$ & 0.895 & $.557-1.437$ \\
\hline $40+^{a}$ & - & - & - & - & - & - & - & - \\
\hline \multicolumn{9}{|l|}{ Marital status } \\
\hline Never married & $0.356^{* * *}$ & $.293-.432$ & 1.016 & $.778-1.326$ & 1.010 & $.742-1.375$ & 1.149 & $.640-2.065$ \\
\hline Ever Married ${ }^{a}$ & - & - & - & - & - & - & - & - \\
\hline \multicolumn{9}{|l|}{ Age at sexual debut } \\
\hline$<15$ & $0.410^{* * *}$ & $.327-.513$ & 0.875 & $.656-1.167$ & 0.889 & $.637-1.242$ & 0.745 & $.407-1.366$ \\
\hline $15+^{\mathrm{a}}$ & - & - & - & - & - & - & - & - \\
\hline \multicolumn{9}{|l|}{ Ever had ritual sex } \\
\hline Yes & 0.706 & $.463-1.075$ & 1.172 & $.724-1.898$ & 0.822 & $.434-1.556$ & $2.399^{*}$ & $1.053-5.466$ \\
\hline $\mathrm{No}^{\mathrm{a}}$ & - & - & - & - & - & - & - & - \\
\hline \multicolumn{9}{|c|}{ Number of life time partners } \\
\hline 1 & $0.103^{* * *}$ & $.068-0.156$ & $0.173^{* * *}$ & $.099-.301$ & $0.117^{* * *}$ & $.059-.234$ & 0.500 & $.184-1.356$ \\
\hline 2 & $0.351^{* * *}$ & $.274-.449$ & $0.423^{* * *}$ & $.319-.562$ & $0.438^{* * *}$ & $.317-.605$ & $0.314^{* * *}$ & $.165-.599$ \\
\hline 3 & $0.586^{* * *}$ & $.468-.734$ & $0.605^{* * *}$ & $.466-.786$ & $0.582^{* * *}$ & $.430-.787$ & $0.513^{*}$ & $.286-.921$ \\
\hline 4 & $0.447^{* * *}$ & $.327-.610$ & $0.454^{* * *}$ & $.318-.649$ & $0.378^{* * *}$ & $.243-.589$ & 0.705 & $.365-1.363$ \\
\hline $5^{\mathrm{a}}$ & - & - & - & - & - & - & - & - \\
\hline \multicolumn{9}{|l|}{ Type of residence } \\
\hline Urban & $1.912^{* * *}$ & $1.588-2.303$ & $2.024^{* * *}$ & $1.567-2.615$ & $2.311^{* * *}$ & $1.715-3.112$ & 1.652 & $.916-2.908$ \\
\hline Rural $^{a}$ & - & - & - & - & - & - & - & - \\
\hline \multicolumn{9}{|l|}{ Region } \\
\hline Central/Northern & $0.537^{* * *}$ & $.452-.639$ & $0.591^{* * *}$ & $.476-.733$ & $0.573^{* * *}$ & $.450-.729$ & 0.719 & $.415-1.246$ \\
\hline Southern ${ }^{a}$ & - & - & - & - & - & - & - & - \\
\hline \multicolumn{9}{|l|}{ Religion } \\
\hline Catholic & 1.107 & $.807-1.518$ & 1.443 & $.931-2.237$ & 0.820 & $.269-2.503$ & $2.426^{*}$ & $1.228-4.793$ \\
\hline Other Christian & 1.131 & $.855-1.498$ & 1.441 & $.971-2.137$ & 0.873 & $.291-2.623$ & 1.300 & $.805-2.098$ \\
\hline Muslim ${ }^{a}$ & - & - & - & - & - & - & - & - \\
\hline \multicolumn{9}{|l|}{ Level of education } \\
\hline None & 1.111 & $.786-1.570$ & 1.262 & $.799-1.993$ & $2.438^{* *}$ & $1.434-4.144$ & 0.395 & $.150-1.035$ \\
\hline Primary & 0.889 & $.738-1.072$ & 1.194 & $.932-1.528$ & $1.342^{*}$ & $1.007-1.787$ & 0.952 & $.540-1.679$ \\
\hline Secondary $+{ }^{a}$ & - & & - & - & - & - & - & - \\
\hline \multicolumn{9}{|l|}{ Wealth index } \\
\hline Poor & $0.575^{* * *}$ & $.468-.707$ & 0.787 & $.598-1.036$ & 0.753 & $.546-1.040$ & 1.123 & $.629-2.004$ \\
\hline Medium & $0.788^{*}$ & $.630-.988$ & 0.757 & $.562-1.019$ & $0.606^{* *}$ & $.422-.871$ & $1.928^{*}$ & $1.057-3.517$ \\
\hline Rich $^{a}$ & - & - & - & - & - & - & - & - \\
\hline \multicolumn{9}{|l|}{ Circumcision status } \\
\hline Circumcised & $1.341^{* *}$ & $1.103-1.631$ & 1.177 & $.871-1.590$ & - & - & - & - \\
\hline Not circumcised ${ }^{a}$ & - & - & - & - & - & - & - & - \\
\hline \multicolumn{9}{|l|}{ Age at circumcision } \\
\hline$<10$ & 0.879 & $.531-1.455$ & - & - & - & - & 1.433 & $.737-2.787$ \\
\hline $10-14$ & 0.855 & $.549-1.332$ & - & - & - & - & 1.409 & $.787-2.520$ \\
\hline
\end{tabular}


Table 3 Respondent's odds of being HIV-positive by selected background characteristics (Continued)

\begin{tabular}{|c|c|c|c|c|c|c|c|c|}
\hline $15+^{a}$ & - & - & - & - & - & - & - & - \\
\hline \multicolumn{9}{|c|}{ Type of circumciser } \\
\hline Traditional & 1.025 & $.641-1.637$ & - & - & - & - & 0.901 & $.478-1.699$ \\
\hline Medical $^{a}$ & - & - & - & - & - & - & - & - \\
\hline Constant & - & - & $0.271^{* * *}$ & - & 0.457 & - & $0.209^{* *}$ & - \\
\hline
\end{tabular}

${ }^{*} p<0.050 ;{ }^{* *} p<0.01 ;{ }^{* * *} p<0.001 ;{ }^{a}$ Reference category

being HIV+ compared to Muslim men who have undergone circumcision.

The other significant factors are age, number of lifetime sexual partners and the wealth index. While age and lifetime sexual partners influence circumcised men in the same way as they influence other models, the wealth index influences circumcised men differently: circumcised men who are in the middle tertile had higher odds of being HIV+ compared to the rich men.

\section{Discussion}

Though statistically insignificant, our paper shows that circumcised men in Malawi have a higher HIV prevalence rate $(12 \%)$ than the uncircumcised men (10 \%). However, the circumcision in this context is mainly traditional circumcision as voluntary medical male circumcision was introduced in 2011, a year after these data were collected. This is contrary to the literature, which suggests that even traditional male circumcision is highly effective in HIV prevention [35]. However, our general model shows that other factors exhibited significant influence on the HIV status. These are age, marital status, number of lifetime sexual partners, type of residence and region. The mode of HIV transmission in Malawi is predominantly heterosexual and as such, it is also expected that individuals with higher levels of exposure to sexual intercourse would be more prone to HIV infection than those with lower levels of exposure to sexual intercourse. While our findings on age and number of lifetime sexual partners appear to confirm this assertion, our result on the effect of marital status deviates from this assertion. The never married are 1.3 times more likely to be HIV+ than the ever married men. Even though our study did not measure the actual number of times an individual had sexual intercourse, it is often assumed that the married have a higher coital frequency than the unmarried persons. It is also not very clear why men in the Northern and Central Regions have higher HIV prevalence than their counterparts in the Southern Region. However, urban areas have in many cases been found to have a higher HIV prevalence rate than rural areas $[36,37]$ and this is the case for Malawi as well.

Among the circumcised men (Model IV), age and number of lifetime sexual partners remain dominant as correlates of HIV status. Interestingly, however, this model appears to provide clues as to why there is no significant difference between circumcised and uncircumcised men in terms of HIV status. Circumcised men who ever had ritual sex are 2.4 times more likely to be diagnosed with HIV than circumcised men who have never had ritual sex. The context of ritual sex in Malawi is not immediately clear. However, evidence of ritual sex after traditional circumcision has been documented in Zambia, one of Malawi's neighboring countries $[24,25]$. This ritual sex is associated with traditional circumcision and exposes men to the risk of HIV infection as use of condom is not emphasized thereby negating the preventive role that male circumcision is supposed to play [24]. Since most of the circumcised men were circumcised by traditional methods in Malawi, there is a high likelihood that the observations made in Zambia [25] could also be at play.

Model IV also confirms observations from elsewhere that Catholics/Christians have higher HIV prevalence than Muslims [38]. Interestingly, circumcised men in the medium wealth index (or the middle class) have significantly higher odds of being diagnosed with HIV than the rich circumcised men. This seems paradoxical as rich men are often viewed as agents of HIV [39] as they are often associated with concurrent multiple sexual relationships [40].

There are some limitations associated with DHS data and that in a way may impact the results of this study. First, DHS data are cross-sectional and hence temporality of the association between male circumcision and HIV infection cannot be absolutely established. Secondly, male circumcision is self-reported, and thirdly, it's impossible to establish when men were circumcised and when they became HIV+ and lastly is the dearth of information around ritual sex and traditional circumcision in Malawi.

\section{Conclusions}

Our study shows that there is a weak association between male circumcision and HIV infection in Malawi. Twelve percent of circumcised men were HIV positive compared to almost $10 \%$ of uncircumcised men. However, most of the circumcised men in this study were circumcised traditionally as the policy to offer medical male circumcision was only introduced in 2011 (a year after the 2010 MDHS was conducted); and hence the results of this study refer mainly to traditional circumcision and should 
be interpreted with a lot of caution. In addition, the finding could be a pointer for the increased need for voluntary medical male circumcision in Malawi, and the need to shun away from the (unsafe) traditional male circumcision practices. Given that most circumcised males were circumcised using traditional methods and that HIV-positive status among circumcised men is significantly associated with ritual sex, it can be deciphered that there is a strong association between traditional circumcision (which may include ritual sex) and HIV infection in Malawi which may be connected to the actual reasons why HIV prevalence is higher among circumcised men than uncircumcised men in Malawi. Therefore, our study shows that traditional male circumcision does not act as a preventive measure to HIV infection in Malawi. However, we acknowledge that the main limitation of this notion is the dearth of information around ritual sex and traditional circumcision in Malawi.

\section{Competing interests}

The authors declare that they have no competing interests

\section{Authors' contributions}

NM conceptualized the study, carried out data analysis and write up. BM did the initial write up and literature review. JM conducted literature review. All authors (NM, BM and JM) participated in the design of the study; read and approved the final manuscript.

\section{Acknowledgements}

This work was also made possible through the generous Core funding to APHRC by the Rockefeller Foundation, William and Flora Hewlett Foundation and the Swedish International Development Agency

\section{Author details \\ ${ }^{1}$ African Population and Health Research Center (APHRC), P.O Box 1078700100 Nairobi, Kenya. ${ }^{2}$ APHRC, Nairobi, Kenya. ${ }^{3}$ Chancellor College, University of Malawi, Zomba, Malawi.}

Received: 5 January 2015 Accepted: 5 October 2015

Published online: 13 October 2015

\section{References}

1. UNAIDS. Fast-Track: ending the AIDS epidemic by 2030. Geneva: UNAIDS; 2014.

2. Vermund SH, Fidler SJ, Ayles H, Beyers N, Hayes RJ. Can combination prevention strategies reduce HIV transmission in generalized epidemic settings in Africa? The HPTN 071 (PopART) study plan in South Africa and Zambia. J Acquir Immune Defic Syndr. 2013;63 Suppl 2:S221-227.

3. Bailey RC, Moses S, Parker CB, Agot K, Maclean I, Krieger JN, et al. Male circumcision for HIV prevention in young men in Kisumu, Kenya: a randomised controlled trial. Lancet. 2007;369(9562):643-56.

4. Sweat M, Morin S, Celentano D, Mulawa M, Singh B, Mbwambo J, et al. Community-based intervention to increase HIV testing and case detection in people aged 16-32 years in Tanzania, Zimbabwe, and Thailand (NIMH Project Accept, HPTN 043): a randomised study. Lancet Infect Dis. 2011;11(7):525-32.

5. McNairy ML, Cohen M, El-Sadr WM. Antiretroviral therapy for prevention is a combination strategy. Curr HIV/AIDS Rep. 2013;10(2):152-8.

6. Mukandavire Z, Bowa K, Garira W. Modelling circumcision and condom use as HIV/AIDS preventive control strategies. Math Comput Model. 2007:46(11-12):1353-72.

7. World Health Organization. Consolidated guidelines on HIV prevention, diagnosis, treatment and care for key populations. Geneva: World Health Organization; 2014
8. Gray RH, Kigozi G, Serwadda D, Makumbi F, Watya S, Nalugoda F, et al. Male circumcision for HIV prevention in men in Rakai, Uganda: a randomised trial. Lancet. 2007;369(9562):657-66.

9. Auvert B, Taljaard D, Lagarde E, Sobngwi-Tambekou J, Sitta R, Puren A. Randomized, controlled intervention trial of male circumcision for reduction of HIV infection risk: the ANRS 1265 Trial. PLoS Med. 2005;2(11):e298.

10. Spreen WR, Margolis DA, Pottage Jr JC. Long-acting injectable antiretrovirals for HIV treatment and prevention. Curr Opin HIV AIDS. 2013;8(6):565-71.

11. Haberer JE, Baeten JM, Campbell J, Wangisi J, Katabira E, Ronald A, et al. Adherence to Antiretroviral Prophylaxis for HIV Prevention: A Substudy Cohort within a Clinical Trial of Serodiscordant Couples in East Africa. PLoS Med. 2013;10(9):e1001511.

12. WHO and UNAIDS announce recommendations from expert consultation on male circumcision for HIV prevention. [http://www.who.int/mediacentre/ news/releases/2007/pr10/en/]

13. World Health Organization. New data on male circumcision and HIV prevention: policy and programme implications: conclusions and recommendations /WHO/UNAIDS. Montreux: WHO/UNAIDS Technical Consultation on Male Circumcision and HIV Prevention: Research Implications for Policy and Programming: 2007; 2007.

14. World Health Organization. Traditional male circumcision among young people: a public health perspective in the context of HIV prevention. Geneva: WHO; 2009.

15. Van Dam JAM. Male circumcision and HIV prevention: directions for future research. Horizons program report. Washington: Population Council; 2000.

16. Alsallaq RA, Cash B, Weiss HA, Longini Jr IM, Omer SB, Wawer MJ, et al. Quantitative assessment of the role of male circumcision in HIV epidemiology at the population level. Epidemics. 2009;1(3):139-52.

17. Wawer MJ, Makumbi F, Kigozi G, Serwadda D, Watya S, Nalugoda F, et al. Circumcision in HIV-infected men and its eff ect on HIV transmission to female partners in Rakai, Uganda: a randomised controlled trial. Lancet. 2009;374:229-37.

18. Doyle SM, Kahn JG, Hosang N, Carroll PR. The impact of male circumcision on HIV transmission. J Urol. 2010;183(1):21-6.

19. Patterson BK, Landay A, Siegel JN, Flener Z, Pessis D, Chaviano A, et al. Susceptibility to human immunodeficiency virus-1 infection of human foreskin and cervical tissue grown in explant culture. Am J Pathol. 2002;161(3):867-73.

20. Morris BJ, Wamai RG. Biological basis for the protective effect conferred by male circumcision against HIV infection. Int J STD AIDS. 2012;23(3):153-9.

21. Liu CM, Hungate BA, Tobian AAR, Serwadda D, Ravel J, Lester R, et al. Male circumcision significantly reduces prevalence and load of genital anaerobic bacteria. mBio. 2013;4(2):e00076.

22. Peltzer K, Simbayi L, Banyini M, Kekana Q. HIV risk reduction intervention among traditionally circumcised young men in South Africa: a cluster randomized control trial. J Assoc Nurses In AIDS Care. 2011;22(5):397-406.

23. Peltzer K, Simbayi L, Banyini M, Kekana Q. HIV risk reduction intervention among medically circumcised young men in South Africa: a randomized controlled trial. Int J Behav Med. 2012;19(3):336-41.

24. Mutombo N. HIV/AIDS implications of initiation practices Among the Lunda-Luvale People Of North Western Zambia. Australasian Rev Afr Stud. 2005;XXVII(2):49-62.

25. United Nations Population Fund. Rapid socio-cultural research as a methodology for informing Sexual and Reproductive Health/HIV/AIDS programming in North Western Province, Zambia. Lusaka: UNFPA; 2005.

26. Gray RH, Kiwanuka N, Quinn TC, Sewankambo NK, Serwadda D, Mangen FW, et al. Male circumcision and HIV acquisition and transmission: cohort studies in Rakai. Uganda Rakai Project Team. AIDS. 2000;14(15):2371-81.

27. Brewer DD, Potterat JJ, Roberts Jr JM, Brody S. Male and female circumcision associated with prevalent HIV infection in virgins and adolescents in Kenya, Lesotho, and Tanzania. Ann Epidemiol. 2007;17(3):217-26.

28. Chikutsa A, Ncube AC, Mutsau S. Male circumcision and risky sexual behavior in zimbabwe: evidence from the 2010-11 Zimbabwe demographic and health survey. Calverton: ICF International; 2013.

29. Wilcken A, Keil T, Dick B. Traditional male circumcision in eastern and southern Africa: a systematic review of prevalence and complications. Bull World Health Organ. 2010;88(12):907-14.

30. Malawi Government. Global AIDS response progress report: Malawi country report for 2010 and 2011. Malawi: Government of Malawi; 2012.

31. Ngalande RC, Levy J, Kapondo CP, Bailey RC. Acceptability of male circumcision for prevention of HIV infection in Malawi. AIDS Behav. 2006;10(4):377-85. 
32. World Health Organization. Progress in scaling up voluntary medical male circumcision for HIV prevention in East and Southern Africa. Brazzaville: World Health Organization. Regional Office for Africa; 2013.

33. World Health Organization: WHO Progress Brief - Voluntary medical male circumcision for HIV prevention in priority countries of East and Southern Africa. In: HIV/AIDS. WHO; 2014.

34. National Statistics Office, ICF Macro. Malawi demographic and health survey 2010. Zomba, Malawi and Calverton, Maryland, USA: NSO and ICF Macro; 2011.

35. Weiss HA, Quigley MA, Hayes RJ. Male circumcision and risk of HIV infection in sub-Saharan Africa: a systematic review and meta-analysis. AIDS. 2000;14(15):2361-70.

36. Gabrysch S, Edwards T, Glynn JR. The role of context: neighbourhood characteristics strongly influence HIV risk in young women in Ndola Zambia. Trop Med Int Health. 2008;13(2):162-70.

37. Ministry of Medical Services, Ministry of Public Health and Sanitation. Kenya AIDS indicator survey. Nairobi: Kenya National AIDS and STI Control Programme (NASCOP); 2007.

38. Ministry of Health, ICF International. 2011 Uganda AIDS indicator survey (UAIS). Kampala, Uganda; Calverton, Maryland, USA: Ministry of Health and ICF International; 2012.

39. Shelton JD, Cassell MM, Adetunji J. Is poverty or wealth at the root of HIV? Lancet. 2005;366(9491):1057-8.

40. Mishra V, Assche SB-V, Macro International Inc. Calverton. Concurrent sexual partnerships and hiv infections: evidence from national population-based surveys. Calverton: Macro International Inc; 2009. DHS Working Papers.

\section{Submit your next manuscript to BioMed Central and take full advantage of:}

- Convenient online submission

- Thorough peer review

- No space constraints or color figure charges

- Immediate publication on acceptance

- Inclusion in PubMed, CAS, Scopus and Google Scholar

- Research which is freely available for redistribution 